\title{
Study on Urban Color Perception and Planning Design
}

\author{
Fuyan $\mathrm{Yu}$ \\ Huanghe Science and Technology College \\ Zhengzhou, China 450005
}

\begin{abstract}
After sort through the relevant information and reference documentations, we conduct a market research to analyze the constituent elements of urban color, design principles, and provide the world's leading color design case for reference in order to discuss the urban color planning. Urban color design is an important part of spiritual life, it makes close contacts with people's daily lives,so that it has become an indispensable part of the activities include people ease the pressure of work, relax ,conduct aesthetic art and others.
\end{abstract}

Keywords-urban color; cognition; experience; urban planning; study

\section{INTRODUCTION}

Urban color reflects the taste and the pursuit of a city, is an important manifestation of urban culture. Every city has its different shades, shapes and characteristics, which bring different feelings to people. Such as Beijing's gray wall tiles and green trees reflect Beijing's vigorous, simple and peaceful cultural heritage; Qingdao use blue as its main tone, clearly shows the elegance of this coastal city.Urban Color and environment penetrate and complementary with each other, develop toward harmonious and beautiful during long-term fusion.

\section{CONSTITUENT ELEMENTS ANALYSIS OF URBAN COLOR}

\section{A. Architecture Color}

Building is the most representative body of a city, therefore, the most artificial control of urban color is building color. Many cities have extremely fine building color outline, such as the University of Frankfurt in France, it embodies the perfect combination of color and architecture. On the sunny side of the main school building evenly distributes the recessed balconies and railings, the outer layer covered with gray and white ceramic tiles, which not only retains the high bright color, but also ensure that not too shining to look, while black ceiling looks more far-reaching than white, gray and yellow colors. The main tone of Beijing traditional buildings are gray color, it brings out the Beijing rustic and deep cultural heritage, these building colors fully reflect the artistry of urban color and they have become an important part of urban color.

\section{B. Garden Color}

Garden color is also a part that occupies a large proportion of human color. Garden color mainly refers to the colors constructed of the garden vegetation and water rocks. Garden color takes the plant green as its predominant color, supplemented by a variety of colors of mountain stones, flowers and fruits, which constitute the unique garden color art. In Spring the branches and leaves are green,all flowers are in full bloom; In Summer the leaves are green, the shades are heavy, flowers blooming like a piece of brocade; In Autumn the leaves are yellow with countless rich fruits; In Winter pine trees and plum tress are covered with white snow. Coupled with the perennial presence of buildings, rocks and water, a colorful four- seasons urban color appeared.

\section{Lighting Color}

Lighting color mainly include artificial lighting and natural lighting. During the day, natural light and the reflect light of buildings are the major part of the urban color, but at night it mainly rely on artificial lighting. In general, the city at night, the night colors constitute of lights are stronger than the colors of natural light during the day. Night lighting can create a colorful world, and therefore, the lighting color becomes an integral part of the city. It keeps the city bright when the sun light disappeared, it creates a diversity of aesthetic to the city and extends the aesthetic time and space for the urban landscape. Many lights together in the city add colors for the city's nightlife.

\section{Nature Color}

Urban nature color mainly refers to the colors brought by the city's natural landscape which including land, vegetation, mountains and rivers. Although city is a product of human development, but the city is still produced in nature, it has materiality itself, so the color decoration will inevitably be affected by natural factors. In contemporary urban color design, rational use natural colors for urban color design has become the essential element for the designer to decorate the city, some cities reach the organism combination between natural color and human color. Such as mountain city Chongqing, the ancients built city on a hill, contemporary designers take fully advantage of this, use the gray white as the predominant color of the buildings, enlarge the green area and make the light green as the predominant color of the city, mountain is city,city is mountain, which make the natural beauty to the extreme. 


\section{PRINCIPLE OF URBAN COLOR PLANNING AND DESIGN}

\section{A. Harmony and Integrity}

When making the color planning for a city, coordination with the surrounding environment is essential. First, in conjunction with the city's own position, consider the city's own reference tone; secondly, in conjunction with the various components of the various parts of the city, planning and design urban color melody on this basis, so as to achieve the overall coordination and harmony effect for the whole city. In the same time also pay attention to the coordination with the surrounding natural scenery, such as the color design of Qingdao, "red tiles,green trees, blue sea and blue sky", bright colors have navigation function for ships, the rest are close to the natural color in order to achieve the harmony and unity of artificial colors and natural colors.

\section{B. Retain Regional Features}

Enter the 21st century, people's pursuit gradually diversified, which requires color planning in different cities should follow different styles. So far many of our cities overcopy the experience of large-scale urban construction, in the color design part there are many similarities, it is now a major problem exists in urban color design. Urban color design should combine with the local environment and custom, and design the urban color with local regional features.

\section{Continuation of the Historical Origin of the City}

Urban color once formed by the history heritage, it will become the carrier of city culture, and continually telling the city's history and culture, so that the urban color design must follow the historical context of the city. The City should maintain its traditional colors, retain the traditional features of this region, in order to meet the growing diversity of aesthetic needs. Even the traditional colors of the city has been destroyed, we should create a unified tone with ancient architecture and historic buildings.

\section{Color Design According to the Urban District Function}

Coordinate the city's color should according to the function of the city, which includes two aspects: on one hand refers to the overall function of the city, on the other hand refers to partition function of the city. Because the functions of the cities are different, so the expressed main colors are different. Tourist city and historical and cultural city, their mainstream colors are different. The color configuration of the city should pay attention to the color scheme of each region within the city. Make color coordination based on functions of functional areas and buildings can effectively solve the urban color chaos and mediocre problems.

\section{NECESSITY AND SIGNIFICANCE OF URBAN COLOR PLANNING}

\section{A. Urban Color is an Important Manifestation of the Quality of Urban People's Life}

Everyone is in pursuit of beauty, color is actually a popular form of beauty. Color not only an important manifestation of the city's beauty, but also an important factor to reflect the quality of urban resident's life. Weather a city construction is good or bad can be expressed in urban color design idea. City with reasonable color coordination and blend with the natural environment shows the city's advanced color design. Meanwhile, the building color is also one of the factors affect the quality of resident's life. For example, some high chroma city taxis, billboards, colorful exhibition cars and glass walls make people feel dizzy, and irritable, later the city manager rationally use the color into a variety of buildings to correct the color deviation, eliminate the irritable mood of the public's mind, enhance the quality of people's life, promote social harmony and stability.

\section{B. The Need of City Grade Improvement}

Urban culture is the soul of a city, without the soul, and then the city will no longer have a life at all. There are many manifestations of the urban culture, and urban color is one of them. Rational planning of urban color is the inherent requirements of city grade improvement and urban cultural origin continuation. The rational allocation of urban color may exhibit the aesthetic taste of the people of the city and demonstrate the city's distinctive character and connotation. With the international trend, now China gradually starts the "convergence"epidemic of international cultural metropolis style, which makes our city's unique cultural heritage gradually loss, therefore, a reasonable coordination of urban color is the only way to enhance the city grade and continue the city's historical heritage.

\section{Urban Color Is an Important Carrier of Urban History and Culture}

If a city randomly destroys the traditional colors during the construction process, it is equivalent to separate historical origin; blindly pursuit of modernization and fashion, sometimes is not progress. For example, China Beijing compared with France Paris, people will feel Paris has a longer history of development, this is because the protection of Beijing's traditional architecture and color during the construction process is not enough, excessively pursuit of high buildings, so that people feel Beijing is a new built city; and Paris in the construction process, integrate the traditional colors into the roads, buildings, etc., so even if they built high buildings, there are also some traditional houses in the suburbs. Although Beijing also has some traditional houses, but retains very little traditions in color decoration, and in the development process Traditional Houses are facing extinction crises, this is not only urban color problem, but also a common problem of domestic urban construction.

\section{The Requirement of Urban Color Pollution Management}

Some cities have ignored the importance of urban color in construction process, which caused much urban color chaos, and then became color pollution, it will not only damage the appearance of the city, but also damaged people's psychology and disrupt the order of people's lives. So rational urban color planning is an important measure to control color pollution and standardize the color coordination. Make color adjustments and specifications in different regions of the city could can 
reduce some unnecessary effects of color, such as the colorful billboards, highly reflective building glass and so on. The reasonable reform of them and urban color pollution management could effectively improve city grade, improve the quality of life of urban residents.

\section{Classic EXAMPLE OF INTERNATIONAL URBAN COLOR PLANNING}

\section{A. La Defense in Paris}

La Defense is located in extension line of Place de la Concorde, Avenue des Champs-Elysees, et Arc de Triomphe, and known as the "Manhattan of Paris", the new city make people fully appreciate the modern elegance of Paris. The new city has unique creation in design and construction aspects, it has magnificent momentum and also you can see some detailed beauty of color. Most of the buildings in the area are consist with popular metal, glass walls and reinforced concretes so it has a strong sense of volume. The whole new city uses clear cold colors with distinct characteristics of the industrial era, but under carefully observation is not difficult to find that there is a lot of embellishment between large building blocks. For example, on the steps at the front right side of the new Arc de Triomphe is mosaic inlaying colorful lattice wall pond, as well as the colorful modern sculpture at the back side of the new Arc de Triomphe, the red arch bridge at the crossing of the road, etc., while performing the industrialized city in the new era there are also some skillful finishing touches which are the classic example of world's urban color planning.

\section{B. The Standardization Construction of Tokyo Urban Color}

Landscape basically aim for the color planning and construction around the main axis of Tokyo city. The color design in this region close to nature which include coastal landscape color, mountains, rivers landscape color and urban greening landscape color, is reflects that the Tokyo color design is based on colors of the building itself. The keynote of special area formed by landscape is to highlight the city's history origin. In comparison, the color design of this area is more stringent, and even developed a special accent color in order to show Tokyo's heavy historical and cultural atmosphere and retain the traditional color culture. General areas mainly include the color control of some remaining buildings, color requirements in this region is less stringent than the first two regions, according to the height of the buildings to decorate with different colors, try to avoid the impact on the normal operation of human's life.

\section{Color Design of Sydney Opera House}

The tile colors of the outer layer of Sydney Opera House are mainly beige and white. Sydney has adequate sunlight, so we do not want to see the Opera House brought light pollution. Australia has a great temperature difference, so for the surface material of the Opera House, the Atlantic day and night salty wet sea breeze will bring enormous damage, the designer chose white and beige ceramic tiles, combined with shell-like external shape, even without cleaning, it also could ensure that the Sydney Opera House's consistently bright and shiny. The interior wall inlay with dark plywood walls and the red smooth leather sheath, combined with red, yellow, pink "day curtain" and the blue, green, brown "Moon curtain", the colorful stage lighting and subtle color structure made the light bustling and diverse, but it will not cause the fretted mood to the people by these complex lights, it is a classics of world's theater construction and planning.

\section{CONCLUSION}

With the gradually increase in the trend of globalization, the communications between countries are increasingly frequent. If a city wants to have attraction, then it must have its own urban color which suitable for its own characteristics, thereby exhibiting a high level of city construction and cultural taste. At present, China's urbanization speed is rapid, urban construction is growing prosperity, but the attendant is the color chaos, color disorder and color pollution. Every city needs a good appearance, but it requires people to work together to achieve. Promotion of the normative construction of urban color still has many places to improve.Enhance the level of color planning is a long way to go.

\section{REFERENCES}

[1] Yang Minhe. Study on the diversity and identity of Hefei urban color landscape [D] Hefei: Hefei University of Technology, 2010.

[2] Duan Lian, Liu Jie.Urban color planning which reflect regional featuretake Guang'an urban color Planning as an example $[\mathrm{J}]$ Construction of small town 2009 (2): 39-45.

[3] Zhang Hailin. Ecological expression of urban public facilities based on guide of design [J] Packaging Engineering, 2014,35 (12): 41. 